\title{
Characterization of Siloxane-poly(methyl methacrylate) Hybrid Films Obtained on a Tinplate Substrate Modified by the Addition of Organic and Inorganic Acids
}

\author{
Sandra Raquel Kunst ${ }^{a, b}$, Lilian Vanessa Rossa Beltrami ${ }^{a}$, Henrique Ribeiro Piaggio Cardoso ${ }^{a}$, \\ Josiane Andrade Santana ${ }^{c}$, Victor Hugo Vitorino Sarmento ${ }^{c}$, \\ Iduvirges Lourdes Müllera, Célia de Fraga Malfatti ${ }^{a}$ \\ ${ }^{a}$ Laboratório de Pesquisa em Corrosão - LAPEC, Universidade Federal \\ do Rio Grande do Sul - UFRGS, Avenida Bento Gonçalves, 9500, Porto Alegre, RS, Brazil \\ ${ }^{b}$ Programa de Pós-graduação em Engenharia de Processos e Tecnologia (PGEPROTEC) da \\ Universidade de Caxias do Sul (UCS), Caxias do Sul, RS, Brazil \\ ${ }^{c}$ Departamento de Química - Campus de Itabaiana - DQCI, Universidade Federal \\ de Sergipe - UFS, Avenida Vereador Olimpio Grande, s/n, Centro, Itabaiana, SE, Brazil
}

Received: May 30, 2014; Revised: February 03, 2015

\begin{abstract}
Tinplate is used to food packaging and other types of packages. The corrosion resistance of the tinplate has been study due the necessity of an alternative to high environmental impact of chromatization process. Therefore protective coatings as hybrid films base elaborations with different acids are studied to improve the barrier effect against corrosion. The objective of this work is characterize hybrid films deposited on a tinplate from a sol made up of the alkoxide precursors 3-(trimethoxysilylpropyl) methacrylate (TMSM), tetraethoxysilane (TEOS) and poly(methyl methacrylate) (PMMA) together with one of three acids (acetic, hydrochloric or nitric acid) and to verify their action against the corrosion of the substrate. The films were obtained by a dip-coating process and cured for 3 hours at $160{ }^{\circ} \mathrm{C}$. The film hydrophobicity was determined by contact angle measurements, and the morphology was evaluated by SEM. FTIR measurements were performed to characterize the chemical structures of the films. The electrochemical behavior of the coatings was evaluated by techniques open circuit potential monitoring (OCP), potentiodynamic polarization and electrochemical impedance spectroscopy (EIS). The results demonstrate that the siloxane-PMMA films improve the protective properties of the tinplate, with the films obtained by acetic acid addition exhibiting the greatest improvement.
\end{abstract}

Keywords: tinplate, hybrid organic-inorganic films, TEOS, EIS, acid hydrolysis

\section{Introduction}

Tinplates are mechanically formable, with fair corrosion resistance and weldability. The main application of tinplates is the fabrication of food packaging and other types of packages. Complete or partial surface coverage of tinplates with a tin oxide passivation layer, $\left(\mathrm{SnO}_{\mathrm{x}}\right)$, mainly $\mathrm{SnO}$ and $\mathrm{SnO}_{2}$ or their hydrated forms, is a characteristic of their quality. Nevertheless, the presence of an excessive quantity of oxides could modify the appearance and weldability of tinplate and its capacity to receive organic coatings. Tinplate packages are currently covered by superficial coatings based on chromate layers, which yield excellent corrosion resistance ${ }^{1}$. Chromatization pre-treatment also enables adhesion between metal and subsequently applied paint layers, and these treatments are easy to apply and economically viable ${ }^{2-4}$. However, these processes involve chemicals that are carcinogenic and environmentally toxic ${ }^{5}$, and therefore they have been subjected to strict governmental regulations.

In order to improve corrosion resistance of the metallic substracts are applied protective coatings as based in the

*e-mail: lvrossa@yahoo.com.br silanes $^{6-8}$. Pretreatments based on siloxane-PMMA have demonstrated promising results, attracting industrial attention. These hybrid films improve the corrosion resistance ${ }^{9}$ and adhesion of organic layers, and they also reduce the environmental impact compared to the chromatization process $^{10}$. Siloxane-PMMA hybrid films have been found to promote excellent anchorage on the tinplate surface ${ }^{11-13}$ for subsequent paint application ${ }^{14}$.

Sol-gel films provide excellent adhesion to the substrate and a suitable protection against corrosion by creating a chemically inert barrier between the metal and aggressive environments. For film deposition, the sol-gel solution is prepared by the hydrolysis and condensation of appropriate metal alkoxides: $\mathrm{M}(\mathrm{OR}) \mathrm{n}$, where $\mathrm{R}$ represents an organic group and $\mathrm{M}$ is a metal ${ }^{15}$. The sol-gel process has successfully been used to prepare silicate gels by hydrolyzing tetrafunctional alkoxide precursors using acid catalysts $^{16}$. The overall process involves hydrolysis and condensation reactions that lead to the growth of clusters that eventually collide and link together to form a gel. The structure of the gel and the aggregation kinetics have been 
addressed in many studies ${ }^{17,18}$. The temperature and time of the heat treatment depend on the kind of precursors and solvents used to produce the coating, but economically it is more interesting to work at lower temperatures and shorter times. Many works report the production of sol-gel coatings with low-temperature heat treatments ${ }^{19-31}$.

The objective of this work is to determine the effects of three different acids (acetic, hydrochloric and nitric acids) added to the formulation of the sol of the siloxane-PMMA hybrid films on the morphological and physical-chemical properties of these films and to evaluate their anti-corrosion performance when deposited on tinplate.

\section{Experimental}

\subsection{Surface preparation}

The tinplate substrates $(2 \mathrm{~cm} \times 6 \mathrm{~cm})$ were rinsed with acetone and dried. Then, they were degreased by immersion in neutral detergent at $70{ }^{\circ} \mathrm{C}$ for 10 minutes. The substrates were then properly washed and dried.

\subsection{Preparation of siloxane-PMMA hybrid films}

All chemicals were obtained commercially. The 3-(trimethoxysilylpropyl) methacrylate (TMSM, Fluka), tetraethyl orthosilicate (TEOS, Aldrich) and ethanol (Mallinckrodt) were used as received. Methyl methacrylate (MMA, Fluka) was distilled to remove the polymerization inhibitor (hydroquinone) and impurities and was then stored in a freezer prior to use. Benzoyl peroxide (BPO, Reagen) was re-crystallized from an ethanol solution. Figure 1 present the structural formulas of the materials used in this work.

The sol-gel reactions were prepared in two steps: the hydrolysis and polycondensation of the silane precursors and the polymerization of methyl methacrylate (MMA) monomer (organic phase). In the first step, TEOS, TMSM, acidified water $(\mathrm{pH}=3)$ and ethanol were mixed and stirred together for $1 \mathrm{~h}$ at $60{ }^{\circ} \mathrm{C}$. In the second step, the radical polymerization of the organic phase was performed in a separate vessel, where MMA and BPO were mixed and stirred together at room temperature until the BPO was completely homogenized. The two reaction solutions were then mixed and stirred for $5 \mathrm{~min}$, forming a transparent sol that was immediately coated on the tinplate samples. The hybrid sols used as the coatings were prepared with the following molar ratios: TEOS:TMSM:MMA = 2:1:6; $\mathrm{H}_{2} \mathrm{O}: \mathrm{Si}=3.5: 1$; ethanol: $\mathrm{H}_{2} \mathrm{O}=1: 2$; BPO:MMA=1:100.

The films were obtained by dip-coating, with a removal rate of $14 \mathrm{~cm} \cdot \mathrm{min}^{-1}$. The coated samples were then air-dried for approximately $10 \mathrm{~min}$. This process was carried out 3 times to increase the uniformity of the films and thus ensure the reproducibility of the electrochemical tests. Then, the coated substrates were heated at $55^{\circ} \mathrm{C}$ for $24 \mathrm{~h}$ and cured at $160{ }^{\circ} \mathrm{C}$ for $3 \mathrm{~h}$. To determine the influence of the acid in the hydrolysis/polycondensation reactions on the structure and anticorrosion properties of the film, hybrid sols were prepared by mixing water with three different acids: acetic $\left(\mathrm{CH}_{3} \mathrm{COOH}\right)$, hydrochloric $(\mathrm{HCl})$ and nitric acid $\left(\mathrm{HNO}_{3}\right)$. Figure 2 shows the flowchart of sample preparation.

\subsection{Experimental techniques}

Scanning electron microscopy (SEM) of a film cross-section was performed in a JEOL-JSM 5800 instrument with an acceleration voltage of $20 \mathrm{kV}$, and Image $\mathrm{J}$ software was then used to determine the film thickness.

The wettability of the hybrid films was determined by contact angle measurement using the sessile drop method in a home-made instrument using image analysis software.
TMSM

3-(trimethoxysilylpropyl) methacrylate<smiles>C=C(C)C(=O)OCCC[Si](OC)(OC)OC</smiles>

MMA

Methyl methacrylate<smiles>C=C(C)C(=O)OC</smiles>

TEOS

Tetraethyl orthosilicate<smiles>CCO[Si](OCC)(OCC)OCC</smiles>

BPO

Benzoyl peroxide<smiles>O=C(OOC(=O)c1ccccc1)c1ccccc1</smiles>

Figure 1. Structural formulas of the materials utilized in this work. 


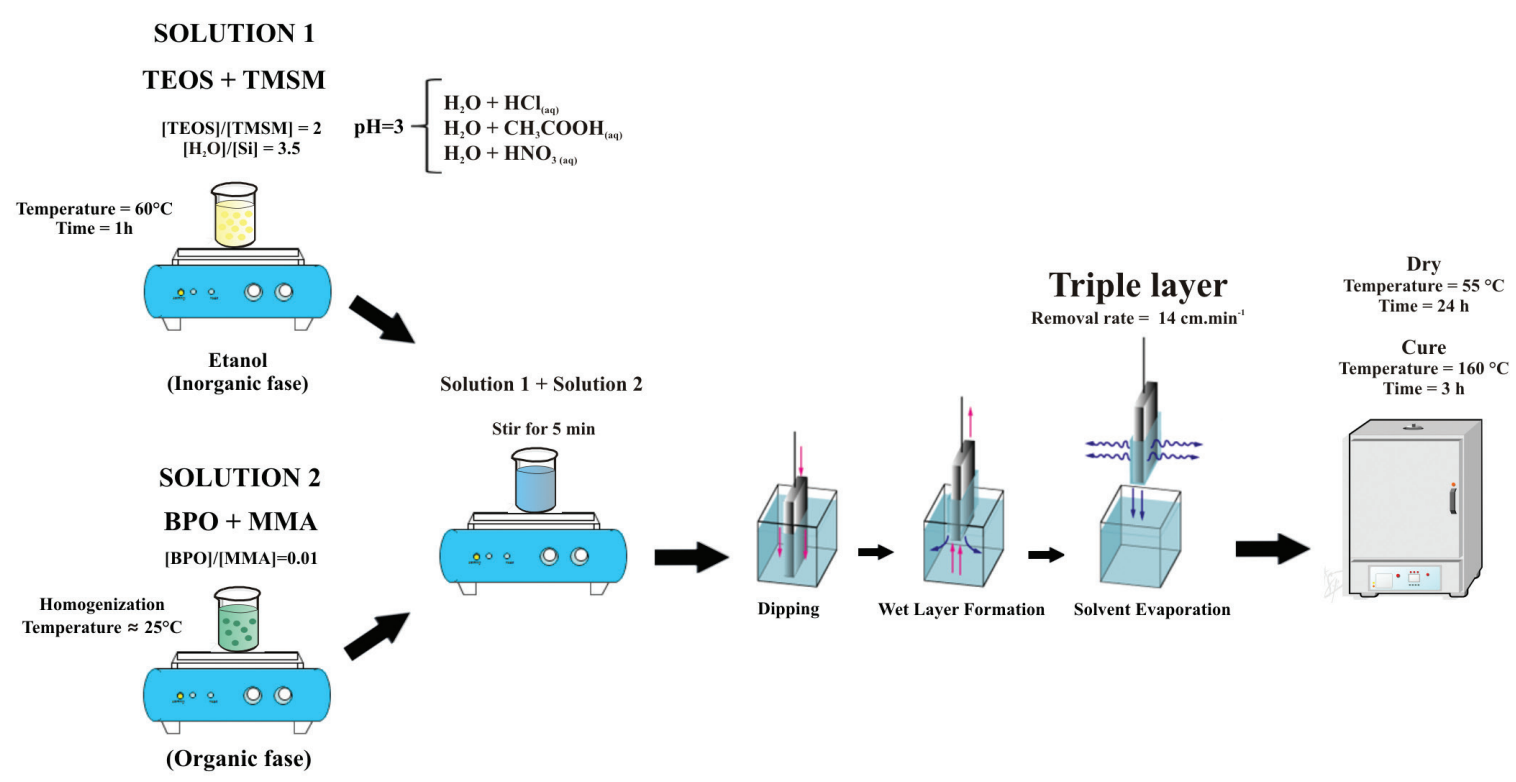

Figure 2. Flowchart of samples preparation.

The Fourier transform infrared spectroscopy (FTIR) measurements were performed with the beam in the mid-infrared range $\left(4000-500 \mathrm{~cm}^{-1}\right)$. The spectra were obtained from the films without a substrate (free-standing films). For this characterization, three different solutions containing the precursors alkoxide 3-(trimethoxysilylpropyl) methacrylate (TMSM) and tetraethoxysilane (TEOS) acidified with different acids (acetic, hydrochloric and nitric acid) were analyzed. The solutions were placed on a Petri plate and heated at $55^{\circ} \mathrm{C}$ for $24 \mathrm{~h}$, and then cured at $160^{\circ} \mathrm{C}$ for $3 \mathrm{~h}$. After the film was obtained, a small amount of each sample was collected for analysis.

The corrosion performance of the coatings was evaluated by open circuit potential $\left(\mathrm{E}_{\mathrm{OCP}}\right)$ monitoring, potentiodynamic polarization curves and electrochemical impedance spectroscopy (EIS) measurements in a $0.05 \mathrm{M}$ $\mathrm{NaCl}$ solution. The electrolyte solution $\mathrm{NaCl}$ in the concentration of $0.05 \mathrm{M}$ ensures the activation of the corrosion process in a relatively short exposure time. Meanwhile, allows the assessment and determination of the effects of the acids used ${ }^{32}$. A three-electrode cell was used to perform these analyses, with a platinum wire as the counter electrode and a saturated calomel electrode (SCE) as the reference electrode. The area of the working electrode was $0.626 \mathrm{~cm}^{2}$. The polarization curves were collected at a scan rate of $1 \mathrm{mVs}^{-1}$. For the EIS measurements, the samples had previously been monitored for 96 hours. The amplitude of the EIS perturbation signal was a sinusoidal $10 \mathrm{mV}$ (rms) perturbation, and the frequency ranged from $100 \mathrm{kHz}$ to $10 \mathrm{~Hz}$ with 10 points per frequency decade, using a Solartron model 1255 frequency response analyzer and a PAR273 potentiostat. For quantitative analysis, the results for the systems that presented the best anticorrosion performance were fitted using electrical equivalent circuits (EEC) with the Z-View ${ }^{\circledR}$ program. The consistency of the experimental data were verified with the Kramers-Kronig transform, and those that did not match with it were removed.

\section{Results and Discussion}

\subsection{Morphological characterization}

Figure 3 presents SEM micrographs of specimens coated with hybrid films formulated with the three acids studied here: acetic (Figure 3a), hydrochloric (Figure 3b) and nitric acids (Figure $3 \mathrm{c}$ ). The film prepared with acetic acid (Figure 3a) exhibits a smooth surface, while the films prepared with $\mathrm{HCl}$ (Figure 3b) and $\mathrm{HNO}_{3}$ (Figure 3c) show the presence of discontinuities and cracks. These results are in agreement with pioneering studies by Pope and Mackenzie ${ }^{33}$. These authors investigated the effects of acid and base catalysts on several properties of gels such as gelation time, porosity, and apparent density. The porosity of the acetic acid catalyzed gel (before and after heat treatment) was significantly lower than the porosities of $\mathrm{HCl}$ and $\mathrm{HNO}_{3}$. A porous film can promote the formation of cracks and discontinuities as seen for these last two acids.

The layer thickness was determined from images of cross sections (Figure 4). The resulting films were relatively dense, and such a dense physical barrier can improve the corrosion protection. The films obtained in acetic and nitric acids presented thicknesses of $1.6 \pm 0.3 \mu \mathrm{m}$ (Figure $4 \mathrm{a}$ ) and $1.37 \pm 0.49 \mu \mathrm{m}$ (Figure $4 \mathrm{~b}$ ), respectively, while the film obtained in $\mathrm{HCl}$ is twice as thick, $3.7 \pm 0.3 \mu \mathrm{m}$, (Figure $4 \mathrm{~b}$ ), which may have favored crack formation in the $\mathrm{HCl}$ film. The viscosity and the number of depositions must be controlled to avoid the formation of thicker films.

\subsection{Physicochemical characterization}

Figure 5 reports the contact angle determination, and Table 1 shows the values obtained for tinplate substrates, both bare substrates and substrates covered with hybrid 


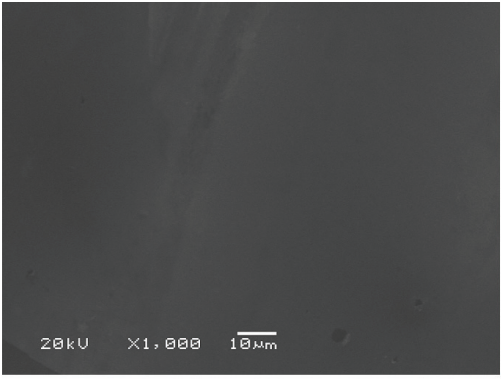

(a)

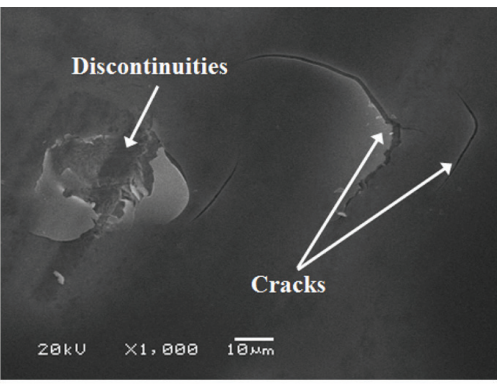

(b)

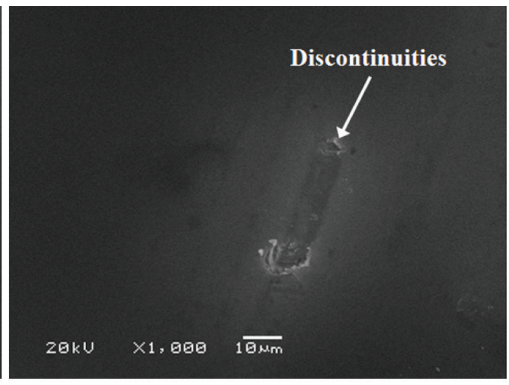

(c)

Figure 3. Micrographs obtained by SEM for the samples: (a) acetic acid, (b) hydrochloric and (c) nitric acid.

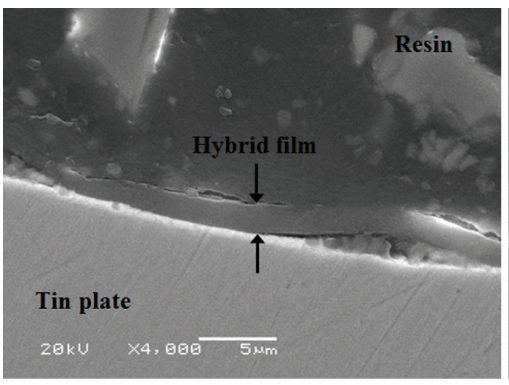

(a)

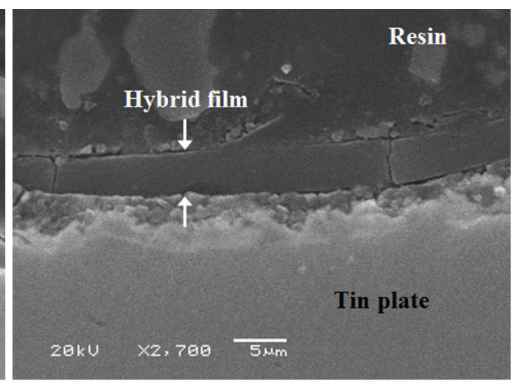

(b)

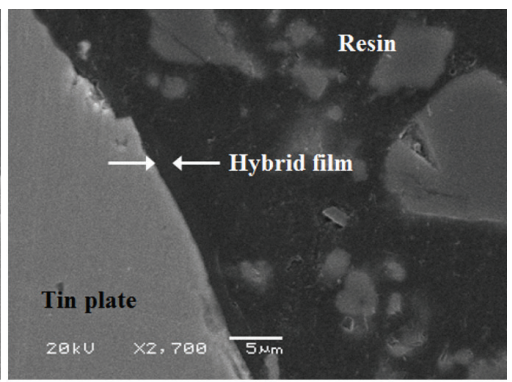

(c)

Figure 4. Cross section micrographs obtained by SEM analysis of hybrid films (a) acetic, (b) hydrochloric and (c) nitric acid.

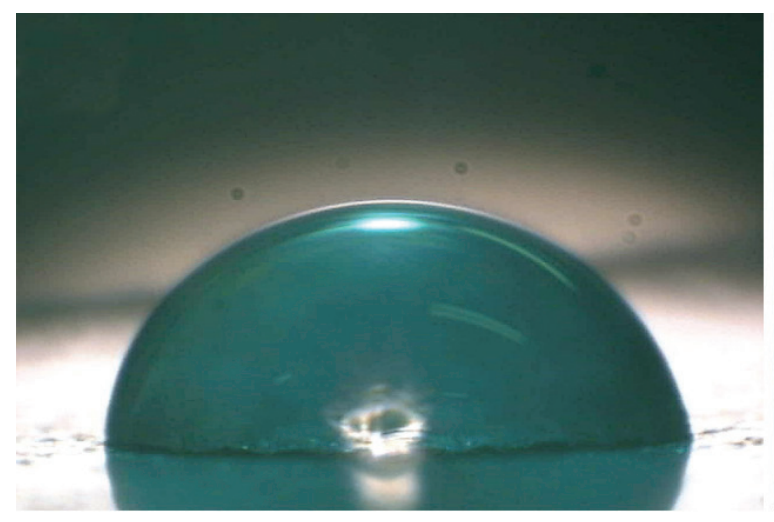

(a)

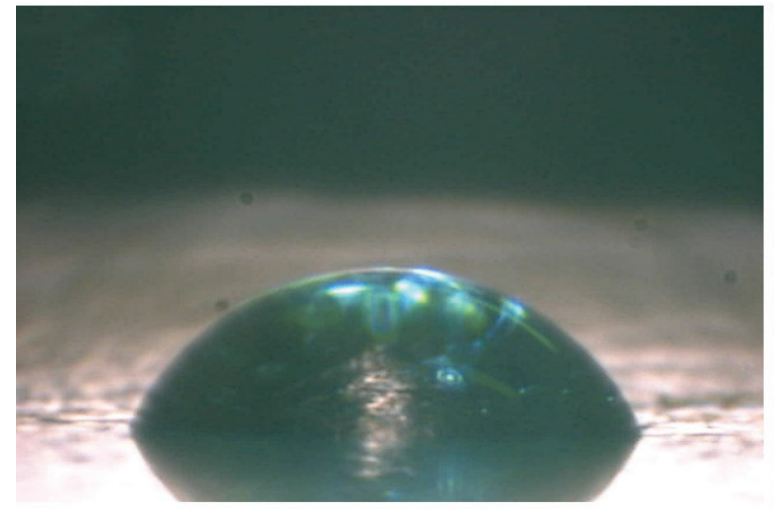

(c)

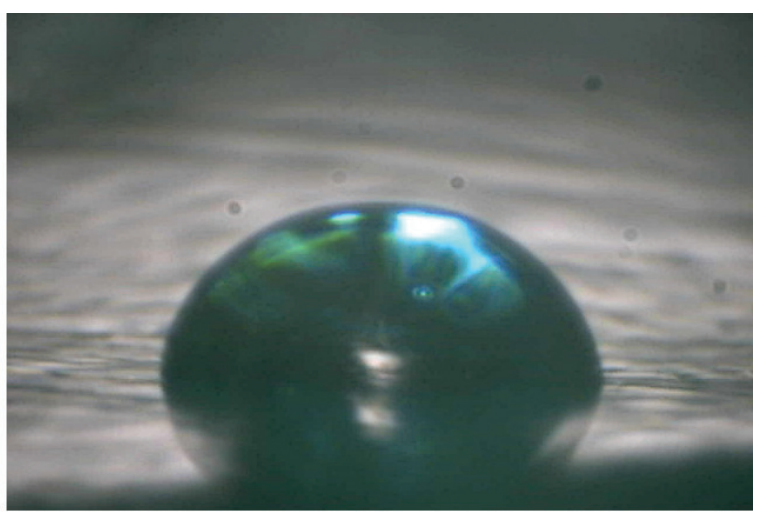

(b)

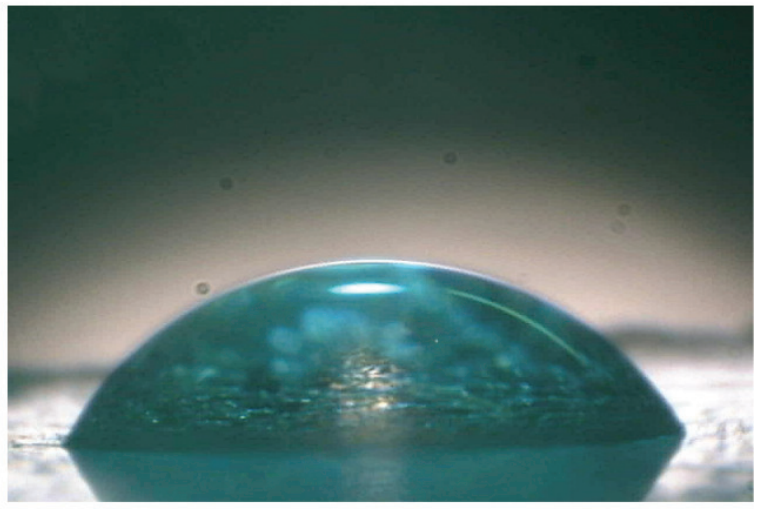

(d)

Figure 5. Images obtained for the contact angle determination by the sessile drop method: (a) tin plate, (b) acetic, (c) hydrochloric and (d) nitric acid. 
films prepared with different acids. All samples exhibited a fairly hydrophilic character. The hybrid films obtained with acetic acid and the tinplate substrate showed the highest contact angle values, and thus a lower wettability compared to films containing hydrochloric and nitric acid. The lowest wettability of the hybrid films with acetic acid can be associated with the regular morphology (Figure 3a) of this film. For tinplate substrates, this behavior is probably due to the presence of tin oxides $(\mathrm{SnOx})$, which result in complete or partial coverage of the surface, increasing the hydrophobicity of the substrate. The siloxane-PMMA films with $\mathrm{HCl}$ and $\mathrm{HNO}_{3}$ showed lower contact angle values compared to those with acetic acid. This behavior may be associated with cracks and discontinuities present in the film (Figure $3 b$ and $3 c$ ) and with the structure of the films as discussed based on the FTIR results presented below.

Figure 6 and Table 2 present the FTIR spectra of the hybrid films prepared with different acids. As seen in Figure 6, strong bands between 1000 and $1200 \mathrm{~cm}^{-1}$ are attributed to $\mathrm{Si}-\mathrm{O}-\mathrm{Si}$, the structural backbone of the hybrid material. The formation of the Si-O-Si layer protects the tinplate substrate. The bands at intermediate frequencies between 900 and $960 \mathrm{~cm}^{-1}$ arise from the $\mathrm{SiOCH}_{2} \mathrm{CH}_{3}$ group due to the incomplete hydrolysis of TEOS. The peaks at approximately $2900 \mathrm{~cm}^{-1}$ were identified and are associated with symmetrical and asymmetrical $\mathrm{CH}$ stretching $\left(\mathrm{CH}_{2}\right.$ and $\mathrm{CH}_{3}$ ) in the aliphatic chain of the organosilane (TMSM). These peaks are all present in the prepared hybrids, suggesting that the type of acid does not influence the formation of the hybrid film by affecting the linkage between the organic and inorganic phases. The broad absorption between $3360 \mathrm{~cm}^{-1}$ and $3620 \mathrm{~cm}^{-1}$ is characteristic of the axial deformation of $\mathrm{OH}$, which could arise from silanol groups $(\mathrm{Si}-\mathrm{OH})$ that were not condensed during the synthesis. In this case, only the siloxane-PMMA sample

Table 1. Contact angle values obtained by the sessile drop method.

\begin{tabular}{cc}
\hline Samples & Average contact angle \\
\hline Tin plate & $88^{\circ} \pm 1.1$ \\
Acetic acid & $89^{\circ} \pm 1.7$ \\
Hydrochloric acid & $70^{\circ} \pm 1.1$ \\
Nitric acid & $57^{\circ} \pm 0.5$ \\
\hline
\end{tabular}

Table 2. FT-IR, peaks assignment as function of peak position.

\begin{tabular}{|c|c|}
\hline Peak position $\left(\mathrm{cm}^{-1}\right)$ & Peak assignment \\
\hline $700-800$ & $\mathrm{C}-\mathrm{H}\left(\mathrm{Si}-\mathrm{CH}_{2}-\mathrm{CH}_{2}-\mathrm{Si}\right)$ stretch \\
\hline $890-920$ & Si-O (Si-OH) stretch \\
\hline $900-960$ & $\begin{array}{l}\text { Asymmetrical stretching Si-O- } \\
\mathrm{C}_{2} \mathrm{H}_{5} \text { groups unhydrolyzed }\end{array}$ \\
\hline $1000-1250$ & $\begin{array}{l}\text { Si-O stretching of Si-O-Si } \\
\text { crosslinked }\end{array}$ \\
\hline $1300-1400$ & $\mathrm{CH}_{2}$ and $\mathrm{CH}_{3}$ scissoring \\
\hline $1600-1670$ & $\mathrm{C}=\mathrm{C}-\mathrm{H}$ axial deformation \\
\hline $1700-1750$ & $\mathrm{C}=\mathrm{O}$ axial deformation \\
\hline $2900-3000$ & $\begin{array}{l}\mathrm{C}-\mathrm{H}\left(\mathrm{CH}_{2} \text { e } \mathrm{CH}_{3}\right) \text { symmetric } \\
\text { and asymmetric stretch }\end{array}$ \\
\hline $3200-3700$ & $\begin{array}{l}\text { Axial deformation of } \mathrm{Si}-\mathrm{OH} \\
\text { group } \mathrm{OH}\end{array}$ \\
\hline
\end{tabular}

with acetic acid exhibited changes in this band, suggesting that the silanols were consumed to form a siloxane network during the preparation of the hybrid sol with acetic acid ${ }^{34}$, resulting in a greater degree of crosslinking. These results were confirmed by SEM demonstrating a crack-free film and contact angle measurements indicating that siloxane-PMMA prepared with acetic acid had the lowest wettability due to the presence of $\mathrm{Si}-\mathrm{O}-\mathrm{Si}$ hydrophobic groups.

\subsection{Electrochemical characterization}

$\mathrm{E}_{\mathrm{OC}}$ values (Figure 7a) demonstrate that coating tinplate with hybrid films increases its corrosion resistance, potentially because the hybrid film acts as a barrier layer between the substrate and the electrolyte. The specimen coated with films prepared using acetic acid exhibited the most promising results, with the highest $\mathrm{E}_{\mathrm{OC}}$ value. Coating with all three types of films decreased $\mathrm{E}_{\mathrm{OC}}$, indicating that modifications occurring during the immersion time are probably associated with the permeation of the electrolyte through the films.

The polarization curves (Figure $7 \mathrm{~b}$ ) show reduced cathodic and anodic current densities for the coated specimens as compared to the uncoated tinplate. The hybrid film prepared with acetic acid again produced the intense effect, resulting in a decrease of the current. No significant difference was observed between the behavior of the specimens coated with films obtained by adding nitric or hydrochloric acid into the sol. These results are in agreement with the characteristics of the various specimens shown in Figure 1, which demonstrate that the hybrid film prepared with acetic acid exhibited the most uniform and least cracked surface upon observation by SEM (Figure 3a).

Figure 8 and Figure 9 present EIS Bode diagrams for uncovered tinplates and for the hybrid films obtained with acetic, hydrochloric and nitric acid after 24, 48, 72 and $96 \mathrm{~h}$ of immersion in a $0.05 \mathrm{M} \mathrm{NaCl}$ solution. The quality of these fits can be verified by the continuous lines in Figures 8 and 9 .

The sheet tinplate was tested to determine the corrosion process associated with the passive tin oxide film. After $48 \mathrm{~h}$ of immersion (Figure $8 \mathrm{~b}$ and Figure $9 \mathrm{~b}$ ), a second time constant appears that is related to the penetration of the electrolyte into the oxide pores, resulting in corrosion

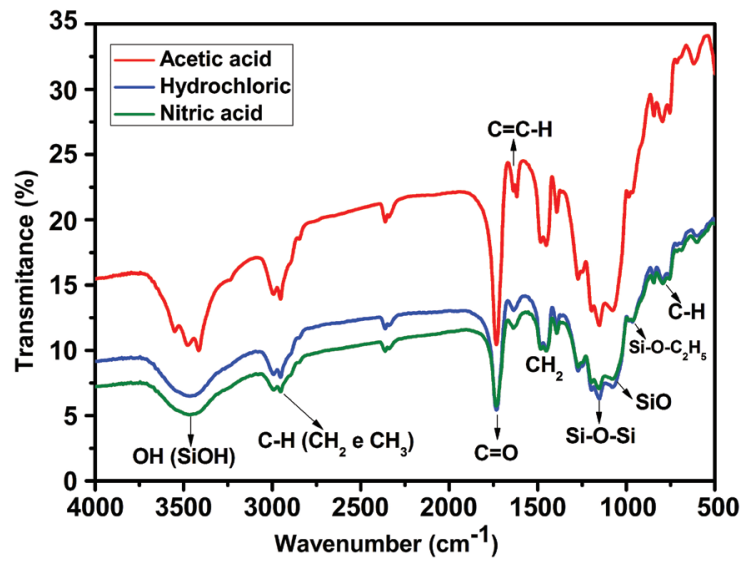

Figure 6. FI-IR spectra of the hybrid films formulated with the three acids studied: acetic, hydrochloric and nitric acid. 


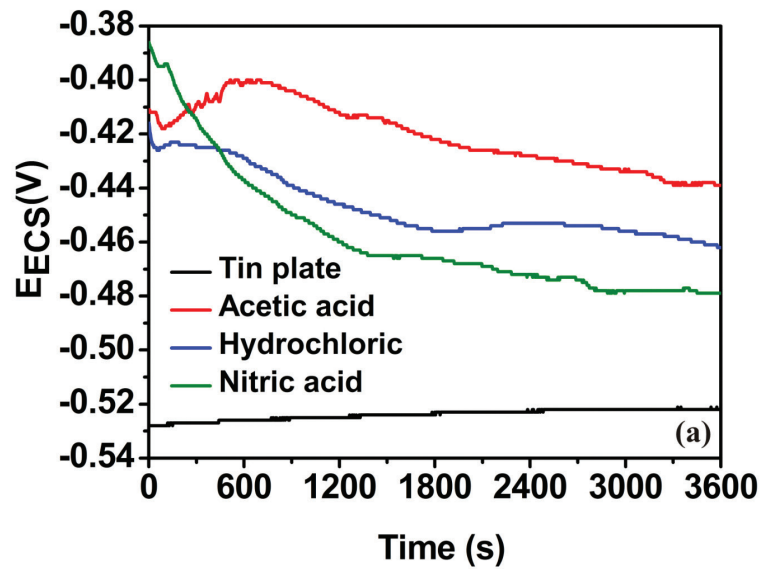

(a)

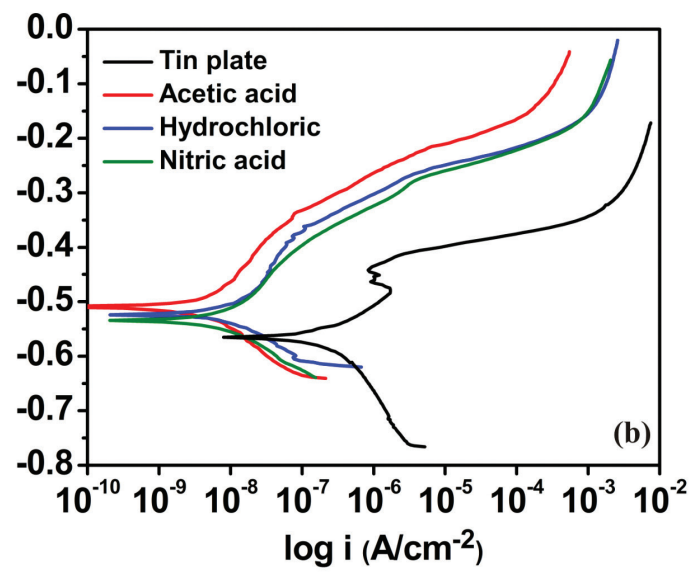

(b)

Figure 7. (a) Open-circuit potential (EOC) and (b) Polarization curves measurements in a $\mathrm{NaCl} 0.05 \mathrm{M}$ solution.
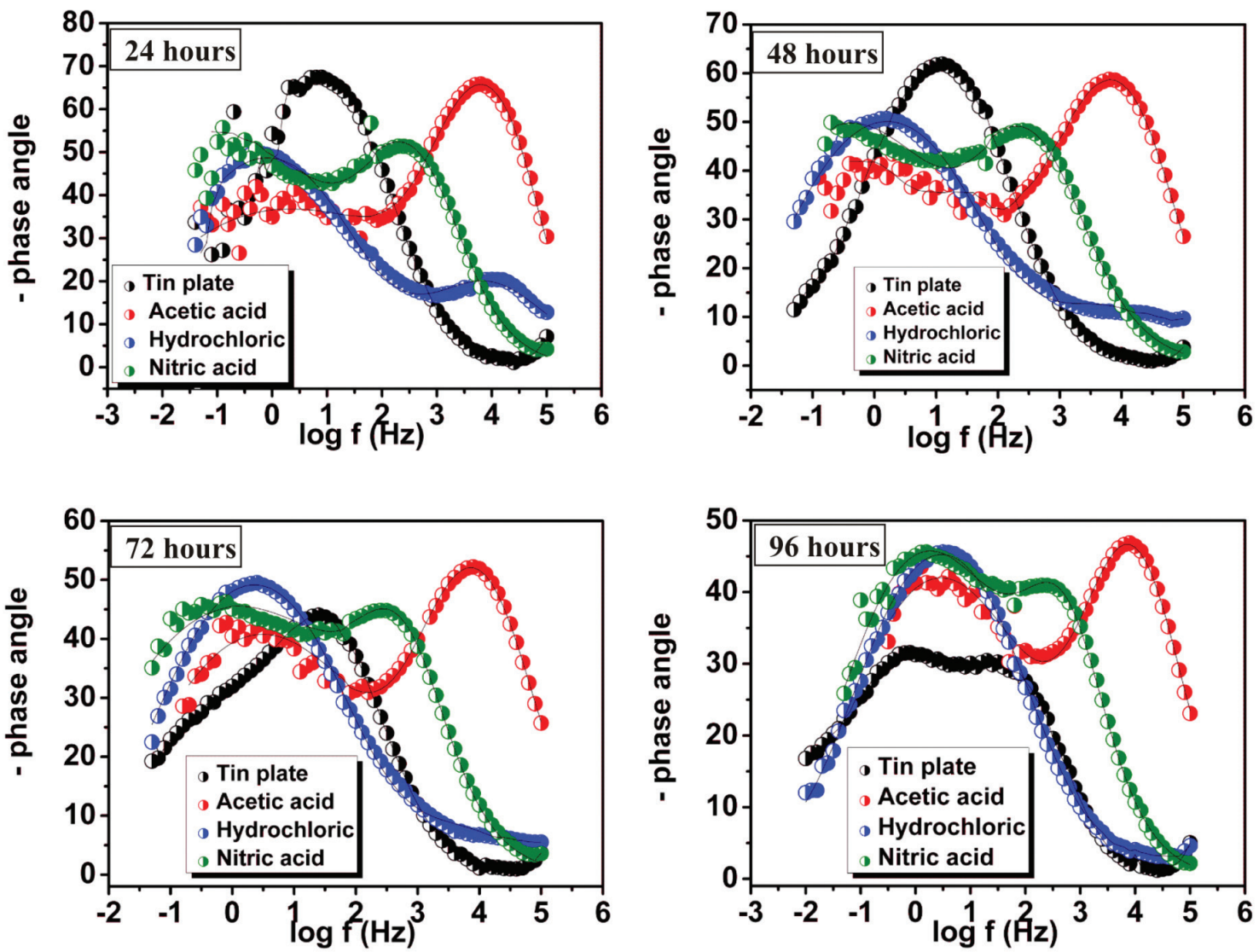

Figure 8. Bode 1 diagrams for different immersion time in a $\mathrm{NaCl} 0.05 \mathrm{M}$ solution.

of the metallic substrate. Tin, tin/iron and finally steel were corroded as confirmed by the red corrosion product observed at the end of the experiment (Figure 10).

The Bode phase angle diagrams show a well-defined time constant in the higher frequency range throughout the entire experimental period for hybrid films prepared with acetic acid, associated with the resistance of the barrier film. This result may be related to the fact that these films are the most homogeneous and have the fewest cracks among the three films tested here, thus enhancing their corrosion resistance.

The hybrid film obtained from a sol with $\mathrm{HCl}$ exhibited a time constant in the low frequency with high peak in the phase angle (Figure 8) starting from 24 hours of immersion in $\mathrm{NaCl}$ solution. This behavior indicates corrosion action instantly the electrolyte has reached the substrate after 

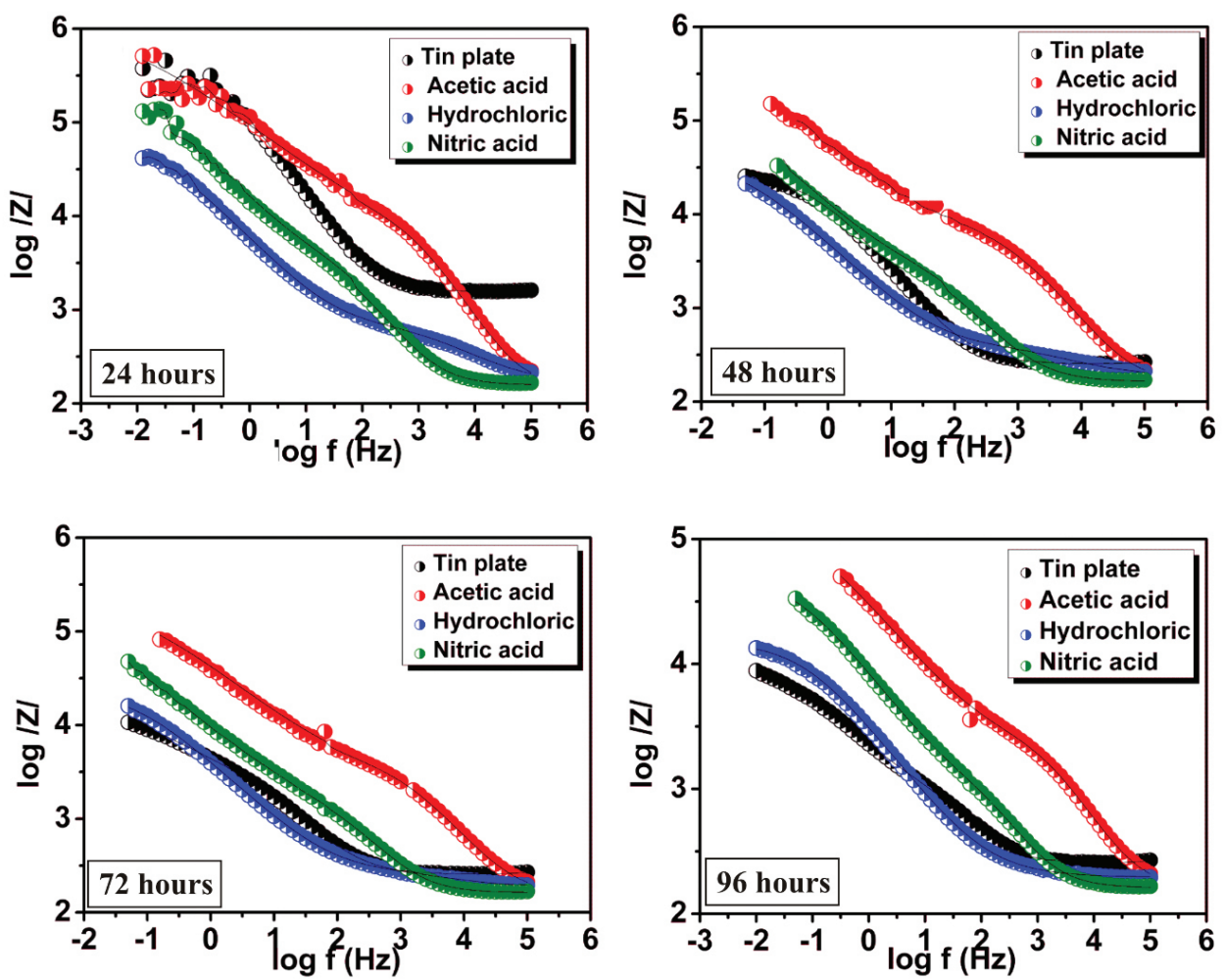

Figure 9. Bode 2 diagrams for different immersion time in a $\mathrm{NaCl} 0.05 \mathrm{M}$ solution.

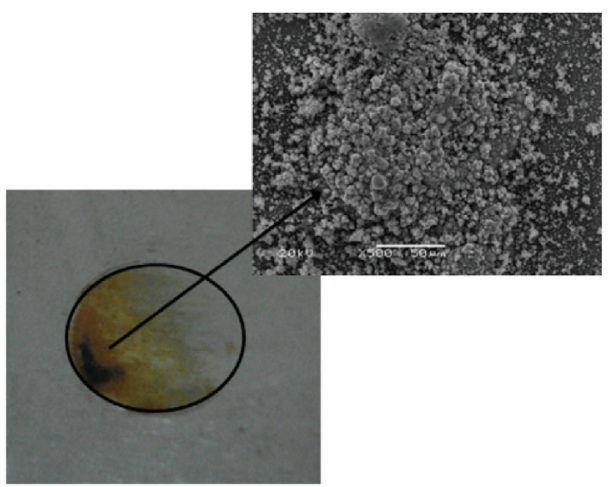

(a)

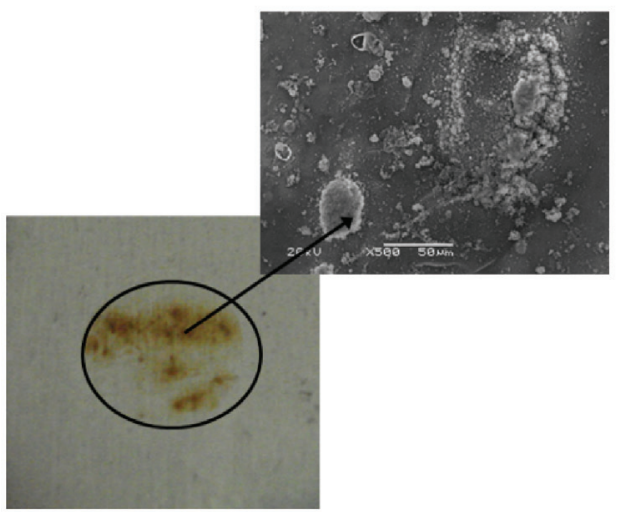

(c)

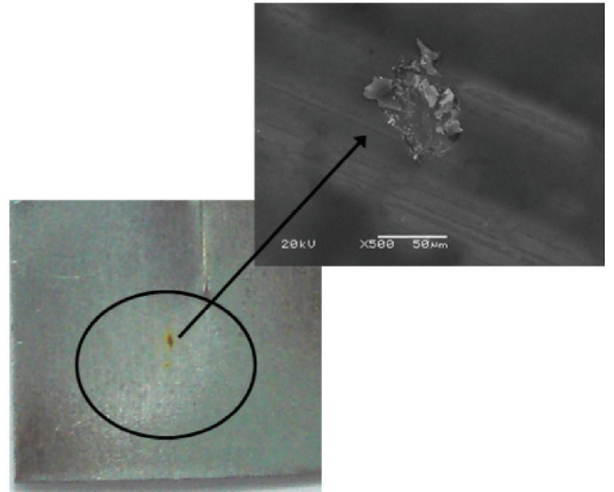

(b)

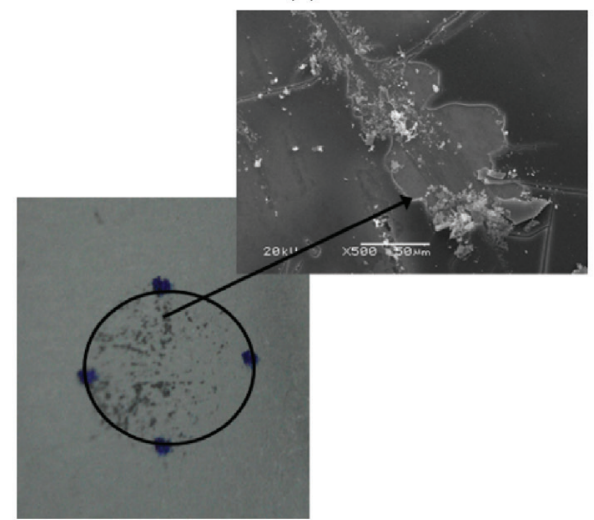

(d)

Figure 10. Images obtained after 96 hours of EIS in a $0.05 \mathrm{M} \mathrm{NaCl}$ solution: (a) tin plate, (b) acetic acid, (c) hydrochloric and (d) nitric acid. 
dipping, as this behavior is identical to that of uncoated tinplate sheet. At 24 hours of immersion, there was another time constant at high frequencies with low peak phase angle corresponding to the barrier promoted by the hybrid film. This barrier promoted by the hybrid film obtained from a sol with $\mathrm{HCl}$ has low resistance to electrolyte, since phase angle shows a low value. With the increase of immersion time, there was a reduction in the strength of the hybrid film (Table 5) until in 72 hours of immersion, the time constantin the high frequency disappears, confirming the complete deterioration of the hybrid film.

For the hybrid film obtained from a sol with nitric acid, one time constant was observed at high frequency with a high peak in the phase angle over all immersion times. This behavior indicates an efficient barrier effect of the hybrid film. There was also a time constant on the average frequency, related to the interfacial process associated with the tin oxide at the substrate surface. The results may be related with lower hydrophobicity of the hybrid film, which facilitates wettability and permeation of the electrolyte which promotes corrosion.

Electrical circuit models were used to fit impedance curves. Table 3, Table 4, Table 5 and Table 6 show the electrical element values obtained by fitting for uncovered and covered samples immersed in a $0.05 \mathrm{M} \mathrm{NaCl}$ solution.
It was not possible to fit impedance curves for the first hour of immersion for hybrid film samples due to their instability in this solution. These instabilities in the first few hours of the EIS experiments can be correlated with the modification of the $\mathrm{E}_{\mathrm{OC}}$ observed during the initial immersion period ${ }^{35}$. These results are related to the interaction of the electrolyte with the film, such as its permeation through the film, which is not an instantaneous process. Other authors ${ }^{13,32}$ have found the same results, and only present EIS data after some hours of immersion. The percent errors shown in brackets in Tables 3-6 verify that the errors involved in the fitting procedure were less than $10 \%$ (less than $5 \%$ in most cases).

For several circuits, the capacitance was substituted by a constant phase element (CPE) to account for the non-ideality of the tinplate and hybrid films. A value of $n=1$ corresponds to a smooth surface, therefore CPE should be substituted by the ideal capacitor $C$. A value of $n=0.5$ suggests a diffusion mechanism or porous material, and $0.5<\mathrm{n}<1$ indicates heterogeneous, rough surfaces or a non-homogeneous current distribution ${ }^{36,37}$. Re is the electrolyte resistance, and RMF and CPEMF represent the medium frequency range resistance and $\mathrm{CPE}$, which were attributed to the top passivating tin oxide ( $\mathrm{SnOx}$ ) layer ${ }^{13}$. RHF and CPEHF represent the higher frequency range elements, associated with the siloxane-PMMA film ${ }^{12,13}$. RLF and CPELF

Table 3. Electrical elements fitted values for tin plate up to $96 \mathrm{~h}$ of immersion in a $0.05 \mathrm{M} \mathrm{NaCl}$ solution. The error \% associated with each parameter value is given in parenthesis.

\begin{tabular}{|c|c|c|c|c|c|}
\hline Tin plate & $1 \mathrm{~h}$ & $24 \mathrm{~h}$ & $48 h$ & $72 \mathrm{~h}$ & $96 \mathrm{~h}$ \\
\hline Fitted circuit & $\overbrace{\underbrace{\mathrm{Re}}_{\text {Pe }}}^{\mathrm{CPEMF}}$ & 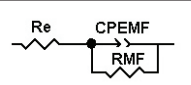 & $\overbrace{}^{\text {Re }} \overbrace{\overbrace{\text { RMF }}^{\text {CPEMF }}}^{\text {RPELLF }}$ & $\overbrace{}^{\text {Re }} \overbrace{\text { CPEMF }}^{\text {CPMF }}$ & 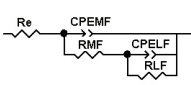 \\
\hline $\operatorname{Re}\left(\Omega . \mathrm{cm}^{2}\right)$ & $168.4(0.9)$ & $1586(0.7)$ & $159.4(0.3)$ & $158.7(0.4)$ & $157.9(0.6)$ \\
\hline CPEHF $\left(\mathrm{Fcm}^{-2}\right)$ & - & - & - & - & - \\
\hline $\mathrm{n}$ & - & - & - & - & - \\
\hline $\operatorname{RHF}\left(\Omega . \mathrm{cm}^{2}\right)$ & - & - & - & - & - \\
\hline CPEMF $\left(\mathrm{Fcm}^{-2}\right)$ & $1.50 \times 10^{-5}(0.9)$ & $1.86 \times 10^{-6}(1.3)$ & $2.17 \times 10^{-5}(1.3)$ & $2.69 \times 10^{-5}(4.4)$ & $2.86 \times 10^{-5}(7.2)$ \\
\hline $\mathrm{n}$ & $0.84(0.3)$ & $0.83(0.3)$ & $0.81(0.3)$ & $0.78(0.8)$ & $0.78(1.6)$ \\
\hline $\operatorname{RMF}\left(\Omega . \mathrm{cm}^{2}\right)$ & $2.14 \times 10^{5}(1.9)$ & $2.85 \times 10^{5}(1.5)$ & $1.25 \times 10^{4}(6.8)$ & $1.22 \times 10^{3}(7.3)$ & $3.91 \times 10^{2}(6.7)$ \\
\hline $\operatorname{CPELF}\left(\mathrm{Fcm}^{-2}\right)$ & - & - & $2.38 \times 10^{-4}(6.9)$ & $1.66 \times 10^{-4}(1.8)$ & $3.02 \times 10^{-4}(0.6)$ \\
\hline $\mathrm{n}$ & - & - & $0.38(5.2)$ & $0.43(1.8)$ & $0.49(0.9)$ \\
\hline $\operatorname{RLF}\left(\Omega . \mathrm{cm}^{2}\right)$ & - & - & $1.04 \times 10^{4}(4.7)$ & $1.16 \times 10^{4}(2.5)$ & $7.28 \times 10^{3}(1.6)$ \\
\hline
\end{tabular}

Table 4. Electrical elements fitted values for siloxane-PMMA with acetic acid up to $96 \mathrm{~h}$ of immersion in a $0.05 \mathrm{M} \mathrm{NaCl}$ solution. The error $\%$ associated with each parameter value is given in parenthesis.

\begin{tabular}{|c|c|c|c|c|}
\hline Acetic acid & $24 \mathrm{~h}$ & $48 h$ & $72 h$ & $96 \mathrm{~h}$ \\
\hline Fitted circuit & 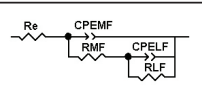 & 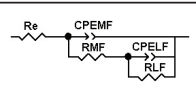 & $\stackrel{\text { Re }}{\text { Re }} \overbrace{\substack{\text { CPEMF } \\
\text { L RMF }}}^{\text {CPEEF }}$ & 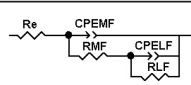 \\
\hline $\operatorname{Re}\left(\Omega \cdot \mathrm{cm}^{2}\right)$ & $166.6(0.9)$ & $165.8(1.2)$ & $157.6(1.1)$ & $159.2(0.7)$ \\
\hline CPEHF $\left(\mathrm{Fcm}^{-2}\right)$ & $7.27 \times 10^{-8}(3.4)$ & $1.37 \times 10^{-7}(4.6)$ & $2.28 \times 10^{-7}(4.6)$ & $3.47 \times 10^{-7}(3.8)$ \\
\hline $\mathrm{N}$ & $0.88(0.3)$ & $0.83(0.5)$ & $0.80(0.5)$ & $0.78(0.4)$ \\
\hline $\operatorname{RHF}\left(\Omega . \mathrm{cm}^{2}\right)$ & $10076(3.2)$ & $6213(2.8)$ & $3585(2.2)$ & $2439(1.6)$ \\
\hline CPEMF $\left(\mathrm{Fcm}^{-2}\right)$ & $4.23 \times 10^{-6}(6.6)$ & $6.77 \times 10^{-6}(3.4)$ & $9.29 \times 10^{-6}(2.3)$ & $1.18 \times 10^{-6}(1.3)$ \\
\hline $\mathrm{n}$ & $0.52(2.7)$ & $0.53(1.6)$ & $0.54(1.1)$ & $0.54(0.6)$ \\
\hline $\operatorname{RMF}\left(\Omega . \mathrm{cm}^{2}\right)$ & $5.81 \times 10^{5}(7.8)$ & $6.11 \times 10^{5}(7.6)$ & $4.57 \times 10^{5}(6.7)$ & $2.45 \times 10^{5}(6.4)$ \\
\hline
\end{tabular}


Table 5. Electrical elements fitted values for siloxane-PMMA with hydrochloric up to $96 \mathrm{~h}$ of immersion in $0.05 \mathrm{M} \mathrm{NaCl}$ solution. The error $\%$ associated with each parameter value is given in parenthesis.

\begin{tabular}{|c|c|c|c|c|}
\hline Hydrochloric & $24 \mathrm{~h}$ & $48 h$ & $72 \mathrm{~h}$ & $96 h$ \\
\hline Fitted circuit & $\sim^{\text {Re }} \overbrace{\substack{\text { CPMEMF } \\
\text { RMF }}}^{\text {CPEEF }}$ & 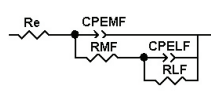 & 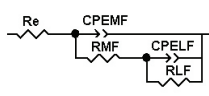 & 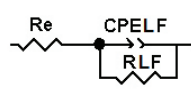 \\
\hline $\operatorname{Re}\left(\Omega . \mathrm{cm}^{2}\right)$ & $157.8(2.8)$ & $181(1.8)$ & $188.2(2.9)$ & 196.3(1.1) \\
\hline CPEHF $\left(\mathrm{Fcm}^{-2}\right)$ & - & - & & - \\
\hline $\mathrm{N}$ & - & - & - & \\
\hline $\operatorname{RHF}\left(\Omega . \mathrm{cm}^{2}\right)$ & - & - & - & - \\
\hline $\operatorname{CPEMF}\left(\mathrm{Fcm}^{-2}\right)$ & $7.62 \times 10^{-6}(7.6)$ & $1.48 \times 10^{-5}(7.7)$ & $2.96 \times 10^{-5}(3.7)$ & - \\
\hline $\mathrm{N}$ & $0.57(3.3)$ & $0.56(0.9)$ & $0.59(3.6)$ & - \\
\hline $\operatorname{RMF}\left(\Omega . \mathrm{cm}^{2}\right)$ & $545(4.6)$ & $242.5(1.5)$ & $151.8(5.3)$ & - \\
\hline CPELF $\left(\mathrm{Fcm}^{-2}\right)$ & $5.31 \times 10^{-5}(3.4)$ & $4.85 \times 10^{-5}(0.4)$ & $4.32 \times 10^{-5}(0.3)$ & $9.61 \times 10^{-5}(0.2)$ \\
\hline $\mathrm{n}$ & $0.61(0.9)$ & $0.66(0.2)$ & $0.68(0.2)$ & $0.61(0.1)$ \\
\hline $\operatorname{RLF}\left(\Omega \cdot \mathrm{cm}^{2}\right)$ & $2.02 \times 10^{5}(7.3)$ & $4.65 \times 10^{4}(1.1)$ & $2.45 \times 10^{4}(0.6)$ & $1.51 \times 10^{4}(0.4)$ \\
\hline
\end{tabular}

Table 6. Electrical elements fitted values for siloxane-PMMA with nitric acid up to $96 \mathrm{~h}$ of immersion in a $0.05 \mathrm{M} \mathrm{NaCl}$ solution. The error $\%$ associated with each parameter value is given in parenthesis.

\begin{tabular}{|c|c|c|c|c|}
\hline Nitric acid & $24 \mathrm{~h}$ & $48 h$ & $72 \mathrm{~h}$ & $96 \mathrm{~h}$ \\
\hline Fitted circuit & 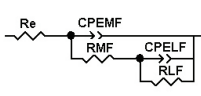 & $\overbrace{}^{\text {Re }} \overbrace{\substack{\text { CPEMF } \\
\text { RMF }}}^{\text {CPELEF }}$ & 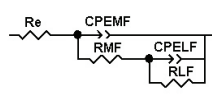 & $\sim_{\sim}^{\text {Re }} \stackrel{\text { CPEMF }}{\text { CPMA }}$ \\
\hline $\operatorname{Re}\left(\Omega . \mathrm{cm}^{2}\right)$ & $158.2(0.5)$ & $164.1(0.4)$ & $161.5(0.4)$ & $161.2(0.3)$ \\
\hline $\mathrm{CPEHF}\left(\mathrm{Fcm}^{-2}\right)$ & $4.12 \times 10^{-6}(3.7)$ & $3.99 \times 10^{-6}(3.4)$ & $4.02 \times 10^{-6}(5.3)$ & $5.20 \times 10^{-6}(4.2)$ \\
\hline $\mathrm{N}$ & $0.77(0.6)$ & $0.78(0.5)$ & $0.79(0.7)$ & $0.78(0.6)$ \\
\hline $\operatorname{RHF}\left(\Omega \cdot \mathrm{cm}^{2}\right)$ & $4392(3.8)$ & $2708(3.2)$ & $1611(4.6)$ & $1280(3.2)$ \\
\hline $\operatorname{CPEMF}\left(\mathrm{Fcm}^{-2}\right)$ & $2.16 \times 10^{-5}(0.9)$ & $2.84 \times 10^{-5}(1.0)$ & $3.53 \times 10^{-5}(1.4)$ & $3.36 \times 10^{-5}(1.0)$ \\
\hline $\mathrm{n}$ & $0.59(0.8)$ & $0.57(0.77)$ & $0.55(0.9)$ & $0.59(0.5)$ \\
\hline $\operatorname{RMF}\left(\Omega \cdot \mathrm{cm}^{2}\right)$ & $6.47 \times 10^{9}(1.2)$ & $8.78 \times 10^{5}(5.4)$ & $1.83 \times 10^{5}(7.7)$ & $5.73 \times 10^{4}(1.7)$ \\
\hline
\end{tabular}

represent low frequency range elements, associated with the tin oxide degradation and/or metal corrosion.

For uncoated tinplate (Table 3 ), only one time constant is observed for 1 and $24 \mathrm{~h}$ of immersion, and this time constant was attributed to the tin oxides. After $48 \mathrm{~h}$ of immersion, tinplate exhibited two overlapping time constants, a similar result as has been observed by other authors ${ }^{13,38}$, indicating the degradation of the tin oxides and probably the metal corrosion, as a new process governed by diffusion apparently begins as indicated by the low value of $n$. This explanation is corroborated by the fact that the initially high resistance declines drastically and that red corrosion products were observed on the electrode surface at the end of the experiment, indicating the formation of iron oxides (Figure 10a).

Two time constants were used to verify the existence of the electrical circuit shown in Table 4. For silane coated tinplate, other authors ${ }^{12,13}$ have also verified the existence of two time constants in a higher frequency region attributed to the presence of the silane layer and in the medium frequency region associated with the tin oxides. In the circuit depicted in Table 4, CPEHF//RHF and CPEMF//RMF are cascade sub-circuits corresponding to the response of the hybrid siloxane-PMMA film in the high frequency range, and of the tin oxides in the medium frequency range, in agreement with similar fitting values shown in Table 3 for tinplate. The results of the fitting procedure show that for the sample coated with hybrid siloxane-PMMA prepared with acetic acid (Table 4), the RHF associated with the coating (hybrid siloxane-PMMA $+\mathrm{SnO}_{2}$ passivating layer) decreased as immersion time increased. This suggests that the electrolyte eventually reaches the substrate, decreasing the barrier effect of these films. CPEHF increased over this time, indicating electrolyte uptake by the hybrid coating, while CPEMF remained almost constant, indicating that the active area does not increase with immersion time, pointing towards a good adhesion between the hybrid coating and the substrate and better anticorrosion properties of this particular hybrid coating.

The analysis of the fitting results for the hybrid film with hydrochloric acid gave two different electric circuits equivalent (Table 5). Corrosion occurs by permeation of the electrolyte through gaps in hybrid film which, with increasing immersion time, promotes the increase of the pore size. This indicates the transition period between the electrode behavior of flat and porous films ${ }^{39}$ which allows the co-existence of flat and porous films ${ }^{40}$.

Thus, the verification of two circuits CPEMF // RMF and CPELF // RLF represent the same phenomenon response. The CPEMF // RMF circuit (24, 48 and 72 hours) represents 
the behavior of a porous film (when the depth of alternating current signal is less than the penetration depth of the pores). Already CPELF // RLF circuit (96 hours) representative of a plan film (when the depth of alternating current signal penetration is greater than the depth of the pore).

The circuit depicted in Table 5 shows that the RMF decreases and CPEMF increases with immersion time, which is indicative of increasing pore depth (an increasing surface area exposed to the electrolyte) and active corrosion. After 72 hours of immersion, the fitting procedure revealed that only one time constant electrical equivalent circuit (Table 5) is associated with the corrosion products (Figure 10c).

The fitting procedure to account for the evolution of the EIS response of the nitric acid hybrid film on tinplate used one equivalent circuit shown in Table 6 with two time constants. As for the acetic acid films, CPEHF//RHF and $\mathrm{CPEMF} / \mathrm{RMF}$ are the cascade sub-circuits making up the response. The high frequency range is associated with the diffusion resistance of the hybrid siloxane-PMMA film, as the micropores represent conductive pathways that can be widened with exposure to the electrolyte, promoting easier

Electrolyte $\mathrm{NaCl}_{(\mathrm{aq})}$
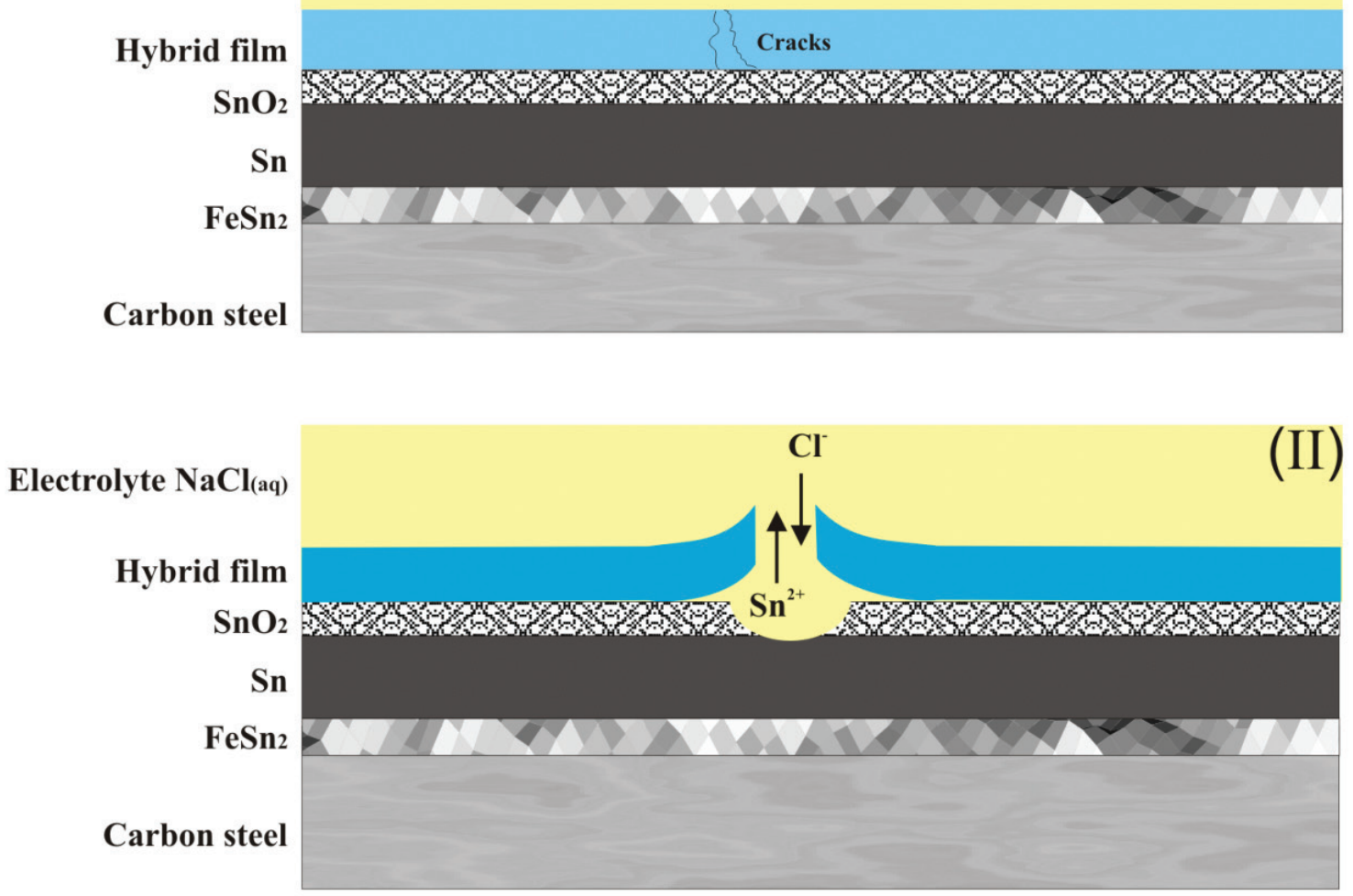

Electrolyte $\mathrm{NaCl}_{(\mathrm{aq})}$

Hybrid film

$\mathrm{SnO}_{2}$

Sn

$\mathrm{FeSn}_{2}$
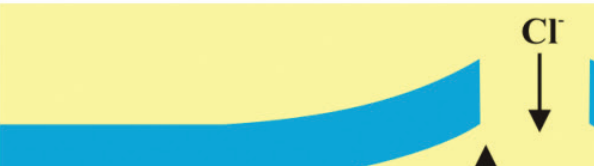

(III)

Carbon steel
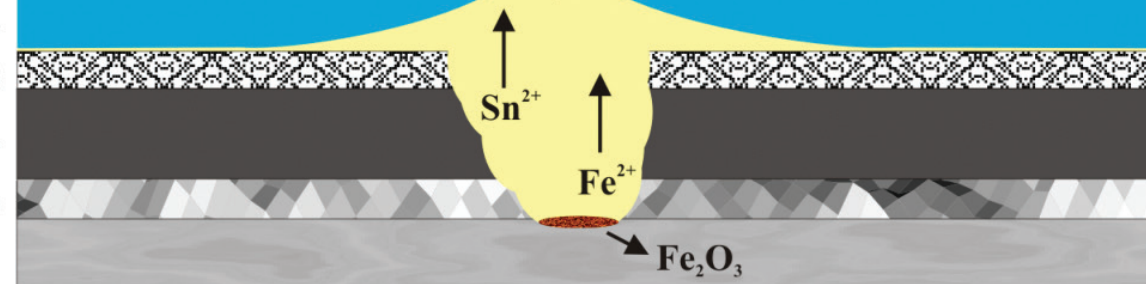

Figure 11. Corrosion mechanism for hybrid film with acid hydrochloric in the electrolyte $\mathrm{NaCl}$ solution. 
access of aggressive species to the substrate surface and explaining the diffusion resistance ${ }^{41}$. The medium frequency range response was attributed to the tin oxides.

In the fitting results for the sample coated with acetic acid containing hybrid films (Table 4), the RHF was associated with the coating pathways (hybrid siloxane-PMMA $+\mathrm{SnO}_{2}$ passivating layer) which decreased with time. For the sample coated with siloxane-PMMA prepared with nitric acid, both RHF and RMF decreased as the immersion time increased and were always less than the corresponding values for the sample coated with the acetic acid film. In the nitric acid film, the RHF was associated with the pathways of the coating system (hybrid siloxane-PMMA $+\mathrm{SnO}_{2}$ passivating layer), while the RMF was associated with the charge transfer resistance of the underlying metallic substrate $(\operatorname{tin}+\operatorname{tin} /$ iron alloy + steel $)$. These results that for the nitric acid film, the electrolyte more easily reaches the substrate and activates the corrosion process, denoting the fragility of this film compared to the hybrid film prepared with acetic acid.

Figure 10 presents the images obtained after 96 hours of immersion in $0.05 \mathrm{M} \mathrm{NaCl}$. Red corrosion products were observed on the electrode surface at the end of the experiment, indicating the formation of iron oxides. For the hybrid films obtained with hydrochloric acid (Figure 10b), abundant but more localized red corrosion products were observed on the surface, also representing iron oxides, and the hybrid films obtained with nitric acid (Figure 10d) showed abundant dark corrosion products indicating the degradation of the tin oxides. In all these cases, the corrosion was much more pronounced than on the sample coated with hybrid films obtained with acetic acid (Figure 10a), corresponding to the expectations based on the results of polarization curves, $\mathrm{E}_{\mathrm{OC}}$ data and EIS diagrams (Figure 8 and Figure 9) and electrical circuit models (Table 4 and Table 5).

Based on the EIS results, a corrosion mechanism for hybrid film with acid hydrochloric in the electrolyte $\mathrm{NaCl}$ solution was proposed, as is shown schematically in Figure 11. According SEM results, the sample surface with acid hydrochloric have cracks. The phase (I) represent the initial exposition the sample with acid hydrochloric to electrolyte. With increasing the time of the sample exposition, the electrolyte permeated the organic coating through cracks and starting the corrosion because of the exposed metal. Electrolyte $\mathrm{NaCl}$ solution (Equation 1), the ions movement increases the electrical conductivity of the solution and the chloride ions propitiate the process of metal corrosion.

\section{References}

1. Cabral AM, Trabelsi W, Serra R, Montemor MF, Zheludkevich $\mathrm{ML}$ and Ferreira MGS. The corrosion resistance of hot dip galvanised steel and AA2024-T3 pre-treated with bis[triethoxysilylpropyl] tetrasulfide solutions doped with Ce(NO3)3. Corrosion Science. 2006; 48(11):3740-3758. http:// dx.doi.org/10.1016/j.corsci.2006.01.010.

2. Endo Y, Sakai T and Takase K. Chromium-free water reducible rust inhibitive paint for metals. FR Patent EP 1500686 A1. 2005 January 26.
$\mathrm{NaCl}+\mathrm{H}_{2} \mathrm{O} \rightarrow \mathrm{Na}^{+}+\mathrm{Cl}^{-}+\mathrm{H}_{2} \mathrm{O}$

The phase (II) indicate that the protective performance of the organic coatings was deteriorated and the ions $\mathrm{Sn}^{2+}$ (Equation 2) flowed from the tin.

$\mathrm{Sn} \rightarrow \mathrm{Sn}^{2+}+2 \mathrm{e}^{-}$

The phase (III) show that part of tin coating was corroded and the carbon steel was exposed to the electrolyte and so began to corrode, loosening iron ions (Equation 3 ). The iron ions react with dissolved oxygen (Equation 4) to yielding the ferrous hydroxide (Equation 5), which is then oxidized and converted to ferric hydroxide $\left(\mathrm{Fe}_{3} \mathrm{O}_{2} \cdot \mathrm{H}_{2} \mathrm{O}\right)$ of reddish color (Equations 6 and 7).

$\mathrm{Fe} \rightarrow \mathrm{Fe}^{2+}+2 \mathrm{e}^{-}$

$1 / 2 \mathrm{O}_{2}+\mathrm{H}_{2} \mathrm{O}+2 \mathrm{e}^{-} \rightarrow 2(\mathrm{OH})^{-}$

$\mathrm{Fe}_{2}++2 \mathrm{OH}^{-} \rightarrow \mathrm{Fe}(\mathrm{OH})_{2}$

$2 \mathrm{Fe}(\mathrm{OH})_{2}+1 / 2 \mathrm{O}_{2}+\mathrm{H}_{2} \mathrm{O} \rightarrow \mathrm{Fe}(\mathrm{OH})_{3}$

$2 \mathrm{Fe}(\mathrm{OH})_{3} \rightarrow 2 \mathrm{Fe}_{2} \mathrm{O}_{3} \cdot \mathrm{H}_{2} \mathrm{O}+\mathrm{H}_{2} \mathrm{O}$

\section{Conclusions}

In the view of the results presented in this work has been completed that the siloxane-PMMA films presented protective properties, indicating the anticorrosive action of these coatings. Among the three acids tested, the acetic acid did not promote the thickest layer, however the resulting film exhibited the best efficiency as an anticorrosion coating for tinplates subjected to a $0.05 \mathrm{M} \mathrm{NaCl}$ solution. FTIR results showed that the siloxane-PMMA samples prepared with nitric acid had the highest amount of hydrophilic groups, in agreement with the contact angle values. This result may be associated with the cracks and discontinuities present in this film.

\section{Acknowledgments}

The authors would like to acknowledge financial support from CAPES (the Brazilian Government Agency for the Development of Human Resources) and CNPq (the Brazilian National Council for Scientific and Technological Development).

3. Maze E, Mocquery C, Millet B and Espinosa AFI. Use of $\mathrm{MoO} 3$ as corrosion inhibitor, and coating composition containing such an inhibitor. FR Patent WO 2002038686 A2. 2009 April 14

4. Endo Y and Sakai T. Chromium-free metal surface treatment agent. JP Patent EP 1693424 A3. 2006 September 20.

5. Ono S, Tsuge H, Nishi $\mathrm{Y}$ and Hirano S. Improvement of corrosion resistance of metals by an environmentally friendly silica coating method. Journal of Sol-Gel Science and 
Technology. 2004; 29(3):147-153. http://dx.doi.org/10.1023/ B:JSST.0000023849.33761.86.

6. Luo F, Li Q, Zhong XK, Gao H, Dai Y and Chen FN. Corrosion electrochemical behaviors of silane coating coated magnesium alloy in $\mathrm{NaCl}$ solution containing cerium nitrate. Materials and Corrosion. 2012; 63(2):148-154. http://dx.doi.org/10.1002/ maco.201005706.

7. Malfatti CF, Menezes TL, Radtke C, Esteban J, Ansart F and Bonino JP. The influence of cerium ion concentrations on the characteristics of hybrid films obtained on AA2024-T3 aluminum alloy. Materials and Corrosion. Werkstoffe und Korrosion. 2012; 63(9):819-827.

8. Younis AA, Ensinger W, El-Sabbah MMB and Holze R. Corrosion protection of pure aluminium and aluminium alloy (AA7075) in salt solution with silane-based sol-gel coatings. Materials and Corrosion. 2013; 64(4):276-283. http://dx.doi. org/10.1002/maco.201206691.

9. $\mathrm{Hu} \mathrm{H}, \mathrm{Li} \mathrm{N}$, Cheng $\mathrm{J}$ and Chen L. Corrosion behavior of chromium-free dacromet coating in seawater. Journal of Alloys and Compounds. 2009; 472(1-2):219-224. http://dx.doi. org/10.1016/j.jallcom.2008.04.029.

10. Trabelsi W, Dhouibi L, Triki E, Ferreira MGS and Montemor MF. An electrochemical and analytical assessment on the early corrosion behaviour of galvanised steel pretreated with aminosilanes. Surface and Coatings Technology. 2005; 192(23):284-290. http://dx.doi.org/10.1016/j.surfcoat.2004.04.088.

11. Sarmento VHV, Dahmouche K, Santilli CV, Pulcinelli SH and Craievich AF. Small-angle X-ray and nuclear-magnetic resonance study of siloxane-PMMA hybrids prepared by the sol-gel process. Journal of Applied Crystallography. 2003; 36(3):473-477. http://dx.doi.org/10.1107/S0021889803000384.

12. Sakai RT, Cruz FMDL, Melo HG, Benedetti AV, Santilli CV and Suegama PH. Electrochemical study of TEOS, TEOS/ MPTS, MPTS/MMA and TEOS/MPTS/MMA films on tin coated steel in $3.5 \% \mathrm{NaCl}$ solution. Progress in Organic Coatings. 2012; 74(2):288-301. http://dx.doi.org/10.1016/j. porgcoat.2012.01.001.

13. Suegama PH, Sarmento VHV, Montemor MF, Benedetti AV, Melo HG, Aoki IV, et al. Effect of cerium (IV) ions on the anticorrosion properties of siloxane-poly(methyl methacrylate) based film applied on tin coated steel. Electrochimica Acta. 2010; 55(18):5100-5109. http://dx.doi.org/10.1016/j. electacta.2010.04.002.

14. Dóhler H, Ferenz M and Herweth S. Utilização de silanos epóxi-funcionais como aditivos de aderência para revestimentos de liberação de silicone de cura por radiação catiônica. BR Patent PI0603786-0A. 2007 Ago 14.

15. Yang Y-Q, Liu L, Hu J-M, Zhang J-Q and Cao C-N. Improved barrier performance of metal alkoxide-modified methyltrimethoxysilane films. Thin Solid Films. 2012; 520(6):2052-2059. http://dx.doi.org/10.1016/j.tsf.2011.10.041.

16. Vollet DR, Donatti DA and Ibañez Ruiz A. A SAXS study of kinetics of aggregation of TEOS-derived sonogels at different temperatures. Journal of Non-Crystalline Solids. 2001; 288(13):81-87. http://dx.doi.org/10.1016/S0022-3093(01)00607-X.

17. Wang P, Yue Z, Zhang J and Feng S. Reactions and mechanisms of chloroplatinic acid hexahydrate with dimethyldi(4$\mathrm{N}, \mathrm{N}$-dimethylaminophenyl)silane. Inorganic Chemistry Communications. 2011; 14(6):1027-1031. http://dx.doi. org/10.1016/j.inoche.2011.03.063.

18. Wu C-H, Jeng J-S, Chia J-L and Ding S. Multi-nuclear liquid state NMR investigation of the effects of $\mathrm{pH}$ and addition of polyethyleneglycol on the long-term hydrolysis and condensation of tetraethoxysilane. Journal of Colloid and Interface Science. 2011; 353(1):124-130. http://dx.doi. org/10.1016/j.jcis.2010.09.024. PMid:20926094

19. Cambon J-B, Ansart F, Bonino J-P and Turq V. Effect of cerium concentration on corrosion resistance and polymerization of hybrid sol-gel coating on martensitic stainless steel. Progress in Organic Coatings. 2012; 75(4):486-493. http://dx.doi. org/10.1016/j.porgcoat.2012.06.005.

20. Montemor MF and Ferreira MGS. Electrochemical study of modified bis-[triethoxysilylpropyl] tetrasulfide silane films applied on the AZ31 Mg alloy. Electrochimica Acta. 2007; 52(27):7486-7495. http://dx.doi.org/10.1016/j. electacta.2006.12.086.

21. Lamaka SV, Knörnschild G, Snihirova DV, Taryba MG, Zheludkevich ML and Ferreira MGS. Complex anticorrosion coating for ZK30 magnesium alloy. Electrochimica Acta. 2009; 55(1):131-141. http://dx.doi.org/10.1016/j. electacta.2009.08.018.

22. Correa PS, Malfatti CF and Azambuja DS. Corrosion behavior study of AZ91 magnesium alloy coated with methyltriethoxysilane doped with cerium ions. Progress in Organic Coatings. 2011; 72(4):739-747. http://dx.doi. org/10.1016/j.porgcoat.2011.08.005.

23. Barranco V, Carmona N, Galván JC, Grobelny M, Kwiatkowski L and Villegas MA. Electrochemical study of tailored sol-gel thin films as pre-treatment prior to organic coating for AZ91 magnesium alloy. Progress in Organic Coatings. 2010; 68(4):347-355. http://dx.doi.org/10.1016/j. porgcoat.2010.02.009.

24. Galio AF, Lamaka SV, Zheludkevich ML, Dick LFP, Müller IL and Ferreira MGS. Inhibitor-doped sol-gel coatings for corrosion protection of magnesium alloy AZ31. Surface and Coatings Technology. 2010; 204(9-10):1479-1486. http:// dx.doi.org/10.1016/j.surfcoat.2009.09.067.

25. Zucchi F, Grassi V, Frignani A, Monticelli C and Trabanelli G. Influence of a silane treatment on the corrosion resistance of a WE43 magnesium alloy. Surface and Coatings Technology. 2006; 200(12-13):4136-4143. http://dx.doi.org/10.1016/j. surfcoat.2005.02.073.

26. Meiffren V, Dumont K, Lenormand P, Ansart F and Manov $\mathrm{S}$. Development of new processes to protect zinc against corrosion, suitable for on-site use. Progress in Organic Coatings. 2011; 71(4):329-335. http://dx.doi.org/10.1016/j. porgcoat.2011.03.025.

27. Yasakau KA, Carneiro J, Zheludkevich ML and Ferreira MGS. Influence of sol-gel process parameters on the protection properties of sol-gel coatings applied on AA2024. Surface and Coatings Technology. 2014; 246:6-16. http://dx.doi. org/10.1016/j.surfcoat.2014.02.038.

28. Adelkhani H, Nasoodi S and Jafari AH. Corrosion protection properties of silica coatings formed by sol-gel method on Al: The effects of acidity, withdrawal speed, and annealing temperature. Progress in Organic Coatings. 2014; 77(1):142145. http://dx.doi.org/10.1016/j.porgcoat.2013.08.011.

29. Salahinejad E, Hadianfard MJ, Vashaee D and Tayebi L. Influence of annealing temperature on the structural and anticorrosion characteristics of sol-gel derived, spin-coated thin films. Ceramics International. 2014; 40(2):2885-2890. http:// dx.doi.org/10.1016/j.ceramint.2013.10.023.

30. Capelossi VR, Poelman M, Recloux I, Hernandez RPB, Melo HG and Olivier MG. Corrosion protection of clad 2024 aluminum alloy anodized in tartaric-sulfuric acid bath and protected with hybrid sol-gel coating. Electrochimica Acta. 2014; 124:69-79. http://dx.doi.org/10.1016/j.electacta.2013.09.004. 
31. Mohseni M, Bastani S and Jannesari A. Influence of silane structure on curing behavior and surface properties of sol-gel based UV-curable organic-inorganic hybrid coatings. Progress in Organic Coatings. 2014; 77(7):1191-1199. http://dx.doi. org/10.1016/j.porgcoat.2014.04.008.

32. Kozhukharov S, Kozhukharov V, Schem M, Aslan M, Wittmar M, Wittmar A, et al. Protective ability of hybrid nanocomposite coatings with cerium sulphate as inhibitor against corrosion of AA2024 aluminium alloy. Progress in Organic Coatings. 2012; 73(1):95-103. http://dx.doi.org/10.1016/j. porgcoat.2011.09.005.

33. Pope EJA and Mackenzie JD. Sol-gel processing of silica: II. The role of the catalyst. Journal of Non-Crystalline Solids. 1986; 87(1-2):185-198. http://dx.doi.org/10.1016/S00223093(86)80078-3.

34. Van Ooij WJ, Zhu D, Stacy M, Seth A, Mugada T, Gandhi $\mathrm{J}$, et al. Corrosion Protection Properties of Organofunctional Silanes-An Overview. Tsinghua Science and Technology. 2005; 10(6):639-664. http://dx.doi.org/10.1016/S10070214(05)70134-6.

35. Plieth W. Electrochemistry for materials science. Amsterdam: Elsevier; 2008.

36. Jayaraj B, Desai VH, Lee CK and Sohn YH. Electrochemical impedance spectroscopy of porous $\mathrm{ZrO} 2-8$ wt.\% Y2O3 and thermally grown oxide on nickel aluminide. Materials Science and Engineering A. 2004; 372(1-2):278-286. http://dx.doi. org/10.1016/j.msea.2004.01.005.

37. Conde A and de Damborenea J. Electrochemical impedance spectroscopy for studying the degradation of enamel coatings. Corrosion Science. 2002; 44(7):1555-1567. http://dx.doi. org/10.1016/S0010-938X(01)00149-4.

38. Xia D, Song S, Wang J, Bi H, Jiang Y and Han Z. Corrosion behavior of tinplate in $\mathrm{NaCl}$ solution. Transactions of Nonferrous Metals Society of China. 2012; 22(3):717-724. http://dx.doi.org/10.1016/S1003-6326(11)61236-3.

39. Song H-K, Jung Y-H, Lee K-H and Dao LH. Electrochemical impedance spectroscopy of porous electrodes: the effect of pore size distribution. Electrochimica Acta. 1999; 44(20):35133519. http://dx.doi.org/10.1016/S0013-4686(99)00121-8.

40. Frateur I, Deslouis C, Orazem M and Tribollet B. Modeling of the cast iron/drinking water system by electrochemical impedance spectroscopy. Electrochimica Acta. 1999; 44(24):4345-4356. http://dx.doi.org/10.1016/S0013-4686(99)00150-4.

41. Duarte RG, Castela AS and Ferreira MGS. Influence of the solution cation mobility on the water uptake estimation of PVC Plastisol freestanding films by EIS. Progress in Organic Coatings. 2006; 57(4):408-415. http://dx.doi.org/10.1016/j. porgcoat.2006.09.026. 